\title{
On the Road to Affordable and Clean Energy: Assessing the Progress of European Countries Toward Meeting SDG 7
}

\author{
Jana Chovancová ${ }^{1}$, Roman Vavrek ${ }^{2 *}$ \\ ${ }^{1}$ Faculty of Management and Business, University of Prešov in Prešov, Konštantínova 16, 08001 Prešov, \\ Slovak Republic \\ ${ }^{2}$ Faculty of Economics, VŠB - Technical University of Ostrava, Sokolská třída 33, \\ 70200 Ostrava, Czech Republic
}

Received: 3 June 2021

Accepted: 21 September 2021

\begin{abstract}
Long term sustainability of energy is a critically important goal of sustainable development globally. In light of new initiatives such as the UN's Agenda 2030 or the Paris Agreement, assessing the progress of EU countries towards reaching ambitious sustainability goals is inevitable. The aim of the paper is to assess the progress of EU countries toward meeting sustainable development goal on affordable and clean energy. The results of the analysis can be described as balanced and stable, although differences between individual countries are significant in cases of some indicators. Each EU country must, however, take a comprehensive view of SDG7 implementation. Sweden, being the first on the list, as well as Luxembourg, being the last one, both have strengths, yet also areas of improvement. Multi-criteria analysis has thrown a spotlight on the Achilles heel of the EU countries disregard of which might cause serious problems in the future.
\end{abstract}

Keywords: sustainable development goal, energy indicators, EU countries, multi-criteria analysis, comparison

\section{Introduction}

Energy underpins all human activities and is interconnected with human development: it fuelled and accelerated the first industrial revolution more than two centuries ago and, since then, it has significantly contributed to near-continuous economic growth on a global level. Energy services such as mobility, thermal

*e-mail: roman.vavrek@vsb.cz comfort, light, and electricity for devices and industrial processes - these collectively satisfy human needs and are omnipresent in the industrialised world. Although fundamental to economic growth, energy production and consumption is also responsible for many negative effects on the environment and human well-being, such as climate change and global temperature rise caused by increased carbon dioxide emissions into the atmosphere. On the other hand, access to sustainable energy services is a fundamental condition for sustainable development, in terms of poverty eradication, zero hunger, good health and well-being, and quality education. Therefore, 
affordable and clean energy is explicitly mentioned as one of the 17 sustainable development goals (SDGs) presented by the UN in 2015. The transition towards sustainability in energy systems in the European Union is not new, as evidenced by [1-4] and others. In recent years, the EU has embedded this approach in important policy initiatives such as climate and energy policies for 2030 and 2050, circular and bio-economy packages, and its research and innovation programme. In addition, the $7^{\text {th }}$ Environmental Action Plan is fully aligned with global objectives such as the 2030 agenda for sustainable development and the Paris Agreement on climate change [5]. A proposed long-term, climate-neutral strategy [6] stresses that the options it proposes "will radically transform energy systems as well as the agriculture sector, and modernise industrial infrastructure along with transport systems and cities, further affecting all activities of society". Similarly, the European Commission's reflection paper [5] acknowledges the need for "a transition to a low-carbon, climate neutral, resource-efficient and biodiverse economy", which is in full compliance with the United Nations 2030 Agenda and the 17 SDGs. Both documents emphasise that the various dimensions of sustainability are inextricably intertwined.

The paper builds on the premise that Agenda 2030 and the set of SDGs is reachable only when they are adopted and implemented by the UN member states. In order to move towards more sustainable patterns of energy production and consumption, it is necessary to assess the progress in energy-related indicators. This study focuses on the assessment of EU countries, as the EU has expressed its ambition to play a leading role in implementation of the 2030 agenda [7]. The paper monitors and analyses the development of EU countries in achieving SDG 7 via a selected set of energyrelated indicators. The novelty of the chosen approach lies in the fact that it not only enables the evaluation of the achievement of SDG 7 by EU countries, but also identifies the most- and least-influential indicators for making progress in SDG 7, which enables the prioritization of approaches to achieving the goal. Determining the best and worst in the class allows benchmarking of other countries.

The paper is structured as follows: In the first part, we briefly introduce key historical milestones towards sustainable development goals proposed by the UN, along with the position of energy among these goals. The second part is devoted to introducing the methods we apply for assessing the sustainable development of EU countries in terms of reaching SDG 7. The analysis of achievements in SDG 7 across EU countries is divided into two parts: (1) Evaluation of the results of multi-criteria analysis, and (2) Verification of results by benchmarking across countries. In conclusion, we summarise our results and suggest possible policy implications and directions for further research.

\section{Political and Literature Background of Sustainable Development with Regard to Energy}

In 2014, following a decision taken at the $3^{\text {rd }} \mathrm{UN}$ Conference on Sustainable Development $(\mathrm{Rio}+20)$ and after more than a year of intergovernmental work in what was called an Open Working Group, UN member states proposed a set of Sustainable Development Goals, or SDGs [8]. The SDGs build upon decades of work from the United Nations (UN). The first steps can be traced to the 1980s, when the UN established the Commission on Environment and Development (UNCED), which was tasked with creating a global agenda for change in order to address major worldwide social and environmental challenges. It culminated in a paper called "Our Common Future", more commonly known as the Brundtland Report $[9,10]$. The report outlined three fundamental components of sustainable development: environmental protection, economic growth and social equity, recognizing that the three were intrinsically linked. This report is still considered the backbone of the UN's work on sustainable development and has influenced subsequent reports and recommendations published by the UN [11]. Building on the Brundtland Report, the UNCED Rio Earth summit in 1992 resulted in two key documents being produced: Agenda 21 and the Rio Declaration on Environment and Development.

Agenda 21 sought to provide a comprehensive blueprint for action and cooperation amongst nations and communities in order to achieve sustainable development [12]. The central belief of Agenda 21 is that all countries and communities can protect the environment while still experiencing growth. Additionally, Agenda 21 emphasizes the need to harmonize the efforts to develop sustainable development indicators at the national, international and global levels, and to include an elaboration of regularly updated and widely available reports and databases.

Meanwhile, the Rio Declaration, also published at this time, established 27 principles on general rights and obligations of the signatory states intended to create a global partnership, one which respects the interests of all while protecting the integrity of global environmental and developmental systems [13]. Adopted by 178 nations, the Rio Declaration defined the right of people to development, as well as their responsibilities for safeguarding the common environment [14].

In 2000, building on previous agreements, world leaders adopted the Millennium Development Declaration, which defined Millennium Development Goals (MDGs). The adoption of the MDGs was a significant and notable moment for international development, addressing extreme poverty while promoting education, gender equality and environmental sustainability [15].

During the following years the MDGs seemed to gain momentum, with particular progress being made 
around Goal 1: Eradicate extreme poverty and hunger; Goal 2: Achieve universal primary education; and Goal 4: Reduce child mortality [16]. Although this was notable progress, significant work was still needed in order to end hunger, achieve full gender equality, improve health and get every child into school [8]. In addition, there was criticism that the MDGs didn't focus enough on environmental issues, further affirming the need for a renewed set of global goals [17,18]. Critics also pointed out that energy was not explicitly referred to in the MDGs [19].

MDGs came to an end in 2015, and a new set of goals was agreed upon to envision a long-term global development trajectory [20]. The Sustainable Development Goals (SDGs) were developed as part of Agenda 30 [8] to guide nations, funding, policy, NGOs and citizens for the next 15 years. The development of the new set of goals was widely seen as an ambitious challenge, as these goals cover a much broader range of social and environmental issues than their predecessors, aim to be universal (i.e. applicable to both developed and developing countries) and have to serve as guideposts for a difficult transition to sustainable development [21].

The SDGs set out 17 goals, with 169 associated long-term targets and 231 unique indicators covering critical sustainability issues, and outlined how they can be achieved [8]. [22] stress three differences in the SDGs compared to the MDGs: (1) Universalism - the goals shall be implemented by all states - rich and poor - that agreed on the 2030 Agenda; (2) The SDGs are an integrated set of global priorities and objectives that are fundamentally interdependent; and (3) This goaland target-based policy framework requires careful monitoring and evaluation, which shall be part of the implementation process.

During the operational period of the MDGs and negotiation of the 2030 Agenda, it was increasingly recognized that energy underpins economic and social development [23], and that it would not be possible to achieve other sustainability goals without it. [18] and others refer to energy as the 'missing' MDG. In this regard, affordable and clean energy became one of the central themes of the Agenda 2030 [22]. Among the 17 SDGs, energy is mostly focused on in SDG 7, which aims to "ensure access to affordable, reliable, sustainable, and modern energy for all" [8]. SDG 7 is accompanied by five targets to be achieved by 2030 : ensure universal access to affordable, reliable and modern energy services (7.1); increase the share of renewable energy in the global energy mix (7.2); double the global rate of improvement in energy efficiency (7.3); enhance international cooperation to facilitate access to clean energy research and technology (7.a); and promote investment in energy infrastructure and clean energy technology (7.b) [8]. The strong interdependence and indivisibility of SDG 7 with other SDGs has also been recognized by [23-26] and others.

\section{Indicator-Based Assessment of the Energy Performance of EU Countries}

Because of the breadth and complexity of sustainable development, it is natural that the assessment of progress requires the use of statistical tools to collect and evaluate information and to introduce certain measurable characteristics [27]. This fact is mentioned in Chapter 40 of Agenda 21, which emphasizes the need to harmonize the efforts to identify and develop Indicators of Sustainable Development (ISDs) at the national, international and global levels, and include an elaboration of regularly updated and widely available reports and databases that can provide a solid basis for decision-making at all levels [28].

However, some authors argue that evaluation of many diversified indicators can lead to the danger of information overload [29]. [30] and others have stated that an indicator system consisting of a very large number of indicators is difficult to handle in terms of reporting requirements, trade-offs between indicators, and decision- and policy-making processes.

From this perspective, the development of aggregate indicators, i.e. indices that summarize the information contained in the many environmental indicators, becomes of fundamental importance for monitoring sustainable development. Aggregate indicators allow for the simplification of complexity into a single (numeric) value, which readily enables comparison [31] and facilitates policy/decision-makers in their efforts to measure, monitor and report on progress towards meeting sustainable development goals and making informed decisions. The usefulness of aggregate indicators, especially in assessing sustainable development, has been defended by many authors, including [32, 33]. On the other hand, the limitations of such aggregates should be taken into consideration. Regarding monitoring the progress in SDGs, we agree with [27] that using a single indicator that synthesizes the progress towards sustainable development, for a given country and time, would have only limited applications for policy-makers in different fields and sectors due to excessive simplification and generalization. Therefore, we have focused on just one of the 17 SDGs - specifically SDG 7, with the aim of carrying out a comprehensive indicator-based assessment of the performance of EU countries and their achievements regarding this goal. For that purpose, we have selected 8 indicators identified and monitored on the EU level. The indicators are summarized in Table 1. These indicators will serve as an input to assessment methods described in the next section.

\section{Material and Methods}

The aim of the study is a quantitative assessment of EU countries in terms of the achievement of their SDG 7 objectives. In order to achieve this goal, 
Table 1. Set of SDG 7 indicators.

\begin{tabular}{|l|c|c|c|}
\hline \multicolumn{2}{|c|}{ Indicator } & Character \\
\hline SDG_07_10 & I1 & Primary energy consumption per capita & Negative \\
\hline SDG_07_11 & I2 & Final energy consumption per capita & Negative \\
\hline SDG_07_20 & I3 & Final energy consumption in households & Negative \\
\hline SDG_07_30 & I4 & Energy productivity & Positive \\
\hline SDG_07_40 & I5 & Production of renewable energy & Positive \\
\hline SDG_07_50 & I6 & Energy import dependency by products & Negative \\
\hline SDG_07_60 & I7 & Population unable to keep home adequately warm by poverty status & Negative \\
\hline SDG_13_20 & I8 & Total GHG Emissions Including Land-Use Change and Forestry & Negative \\
\hline
\end{tabular}

the CV-TOPSIS technique was selected using 8 energyrelated indicators, which in our opinion are able to provide a comprehensive picture of the progress of EU countries towards SDG 7 in the monitored period of 2010-2017. The data was extracted from EU's official statistic office - Eurostat. In addition to assessing the progress of individual EU member states with regard to particular energy-related indicators, the analysis allows us to determine the most and least influential indicators for making progress in SDG 7 at the EU level, as well as the dependence rate of individual indicators (see Table 1).

The results were processed in MS-Excel, Statistica 13.4 and Statgraphics XVIII, and statistically verified using a wide array of mathematical-statistical methods, including the Shapiro-Wilk test (SW), Analysis of variance $(\mathrm{F})$, Kendall rank coefficient, Kruskal-Wallis test and Levene test (LE).

\section{TOPSIS Technique in the Context of Determining the Importance of an Indicator}

The Technique for Order of Preference by Similarity to Ideal Solution (TOPSIS) is one of the MCDM (multicriteria decision-making) methods of the $21^{\text {st }}$ century, and its primary use is in solving various types of decision problems. [34] identify it as the second-mostused MCDM technique, where the possible alternatives include Analytical Hierarchy Process (AHP), Analytical Network Process (ANP), and Preference Ranking Organization Method for Enrichment Evaluations (PROMETHEE). The frequency of their use is addressed by $[35,36]$ and others, who noted an increasing number of surveys annually in which one could find the use of one of the methods. The choice of the TOPSIS method for the purposes of our research was based on a literature review of its use in the research of other authors.

[37] use this method to assess the energy policy of an EU country and evaluate legislation, action plans and concepts in this area. The application for evaluation of a RES energy technology solution for medium, local district heating systems is performed by [38]. Assessment of sustainable energy development in Baltic Sea Region was performed by [39]. A comparison of renewable energy technologies in 6 countries is dealt with by [40], who work with 6 specific indicators. The TOPSIS technique, which uses 8 indicators divided into 3 dimensions for evaluation of the energy sector in EU countries, can be found in the research of [41]. A group of 14 indicators in 4 dimensions for the evaluation of energy security performance are used by [42]. An even more complex approach to the evaluation of the sustainable development of mineral-resourcebased cities is addressed by [43], who use 25 indicators divided into 5 dimensions, such as economic subsystem, social subsystem or environmental subsystem. This method and its practical application can also be found in the evaluation of selected bio-economic systems [44], the definition of the decarbonisation path in Columbia [45], the kind of biofuel selection [46], energy storage node enterprises [47], urban land use efficiency evaluation [48], resilience evaluation of smart cities [49], evaluation of the energy-environmental efficiency of European transport sectors [50] and in the research of many other authors [51-53].

This method is described in more detail in, among others, [54], and is calculate as follows:

Firstly, a matrix is created (it ranks alternatives according to the respective pre-identified criteria):

$$
D=\left(\begin{array}{ccccc} 
& X_{1} & X_{2} \ldots & X_{j} \ldots & X_{n} \\
A_{1} & x_{11} & x_{12} \ldots & x_{1 j} \ldots & x_{1 n} \\
A_{2} & x_{21} & x_{22} \ldots & x_{2 j} \ldots & x_{2 n} \\
: & : & : & : & : \\
A_{i} & x_{i 1} & x_{i 2} \ldots & x_{i j} \ldots & x_{i n} \\
: & : & : & : & : \\
A_{m} & x_{m 1} & x_{m 2} \ldots & x_{m j} \ldots & x_{m n}
\end{array}\right)
$$

where: $A_{i}=i\left(\right.$ th) alternative, $x_{i j}=$ value of the $j($ th) criterion reached by the $i($ th) alternative

After that, this matrix is normalized: 


$$
r_{i j}=x_{i j} / \sqrt{\sum_{j=1}^{j} x_{i j}^{2}}
$$

where: $r_{i j}=$ normalized value of the $j($ th) criterion, $x_{i j}=$ value of the $j(t h)$ criterion reached by the $i(t h)$ alternative.

The matrix of data obtained is multiplied by the weights of the relevant criteria:

$$
v_{i j}=w_{i j} * r_{i j}
$$

where: $\mathrm{v}_{\mathrm{ij}}=$ weighted normalized value, $\mathrm{w}_{\mathrm{ij}}=$ criterion weight, $r_{i j}=$ normalized value.

Positive Ideal Solution (PIS) and Negative Ideal Solution (NIS) are identified:

$$
H_{j}=\max \left(w_{i j}\right), D_{j}=\min \left(w_{i j}\right)
$$

where: $H_{j}=$ PIS, $D_{j}=$ NIS.

The distance of each real alternative from thus obtained PIS and NIS can be calculated based on the following formula:

$$
d_{i}^{+}=\sqrt{\sum_{j=1}^{k}\left(w_{i j}-H_{j}\right)^{2}}, \quad d_{i}^{-}=\sqrt{\sum_{j=1}^{k}\left(w_{i j}-D_{j}\right)^{2}}
$$

where: $d^{+}=$distance from PIS,$d^{-}=$distance from NIS.

The relative distance from PIS $\left(c_{i}\right)$ is the basic criterion for setting the rank of an alternative. This criterion, by means of the relationship below, considers the two identified distances from the previous step:

$$
c_{i}=\frac{d_{i}^{-}}{d_{i}^{-}+d_{i}^{+}}
$$

where: $c_{i}=$ relative distance from PIS.
The importance of determining the significance of the weights of indicators is given by the third step of its calculation. Thus, it is clear from the above entry that we directly influence the overall result of the TOPSIS technique by weights, i.e. the importance of individual indicators. [47] point to two main approaches to determining the importance of indicators:

- subjective methods,

- objective methods.

The first group, consisting of subjective methods, reflects the personality and individuality of the decisionmaker, who, based on his own (and mostly expert) opinion, determines the importance of individual indicators. Proponents of this approach include [38, 45, 55], who use assessment by a group of experts in the field and pairwise comparisons. The second group of methods assigns the weight of the indicators based on a predetermined mathematical model. Within this group we can find the Mean Weight method [44], Standard Deviation method [56], Mahalanobis-Taguchi System method [42], $\lambda$ bi-capacity model [48], Coefficient of Variance method [28] and many others.

For the purposes of the present research, the Coefficient of Variance method (CV) is used.

$$
w_{j}=\frac{C V_{j}}{\sum_{j=1}^{n} C V_{j}}
$$

where: $\mathrm{CV}_{\mathrm{j}}=$ coefficient of variance of $\mathrm{j}(\mathrm{th})$ criterion.

This approach is more described by [57] and is attractive in various forms, whether in the form of moment characteristics [58, 59], control CV charts $[60,61]$, or a method for determining the importance of indicators in multi-criteria evaluation [28, 62]. By its application, the following weights of 8 evaluated indicators in individual years of the evaluated period are calculated (Fig. 1).

There are no significant differences in weighting between years, when the highest variation range has energy productivity $\left(\mathrm{R}_{\mathrm{I}}=0.041\right)$. The three most important indicators include Final energy consumption

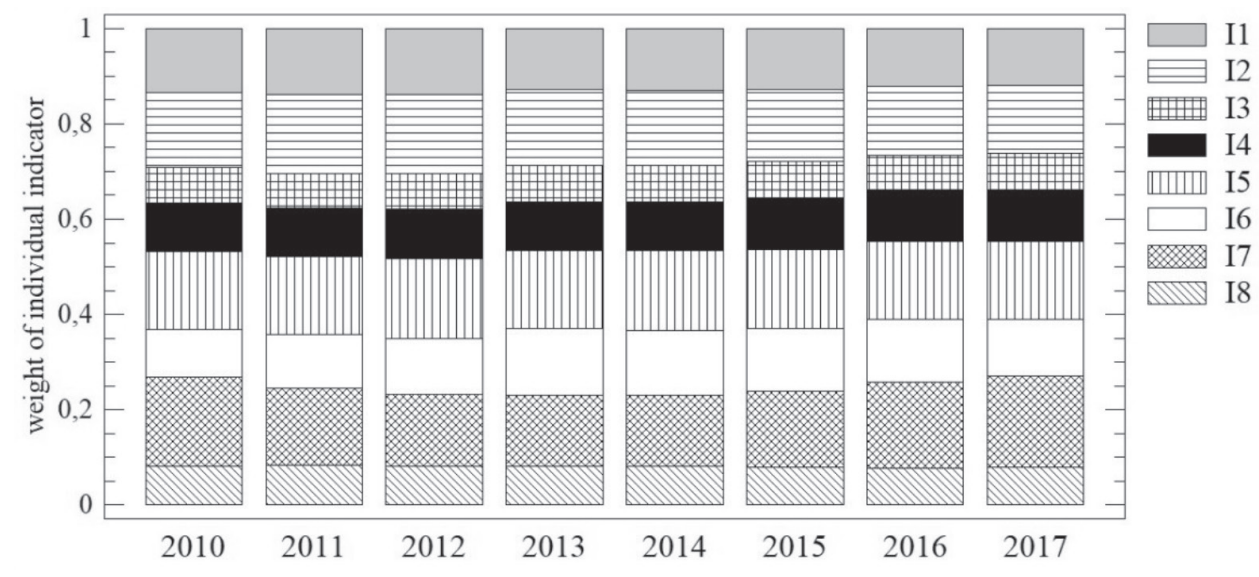

Fig. 1. Weight of monitored indicators assigned by the CV method. 
per capita (I2), Production of renewable energy (I5) and Population unable to keep home adequately warm (I7). Within these indicators we can observe the largest differences between countries. Final energy consumption per capita (I2) and Production of renewable energy (I5) are indicators that are determined by the economic orientation of individual countries, as well as a number of geographical, cultural and political factors, where we see limited potential for reducing disparities between countries. However, in the indicator Population unable to keep home adequately warm by poverty status (I7), we see room for cohesion among EU countries aimed at reducing these disparities. On the other hand, the indicators with the lowest weight are Household energy consumption (I3), with an average weight of $7.6 \%$, and Total GHG emissions (I8), where th e position of countries is relatively balanced.

\section{Results and Discussion}

In the first part of the research, we focus on characterizing the overall results of the multi-criteria evaluation carried out using the CV-TOPSIS technique and 8 indicators. Based on the results of this analysis,
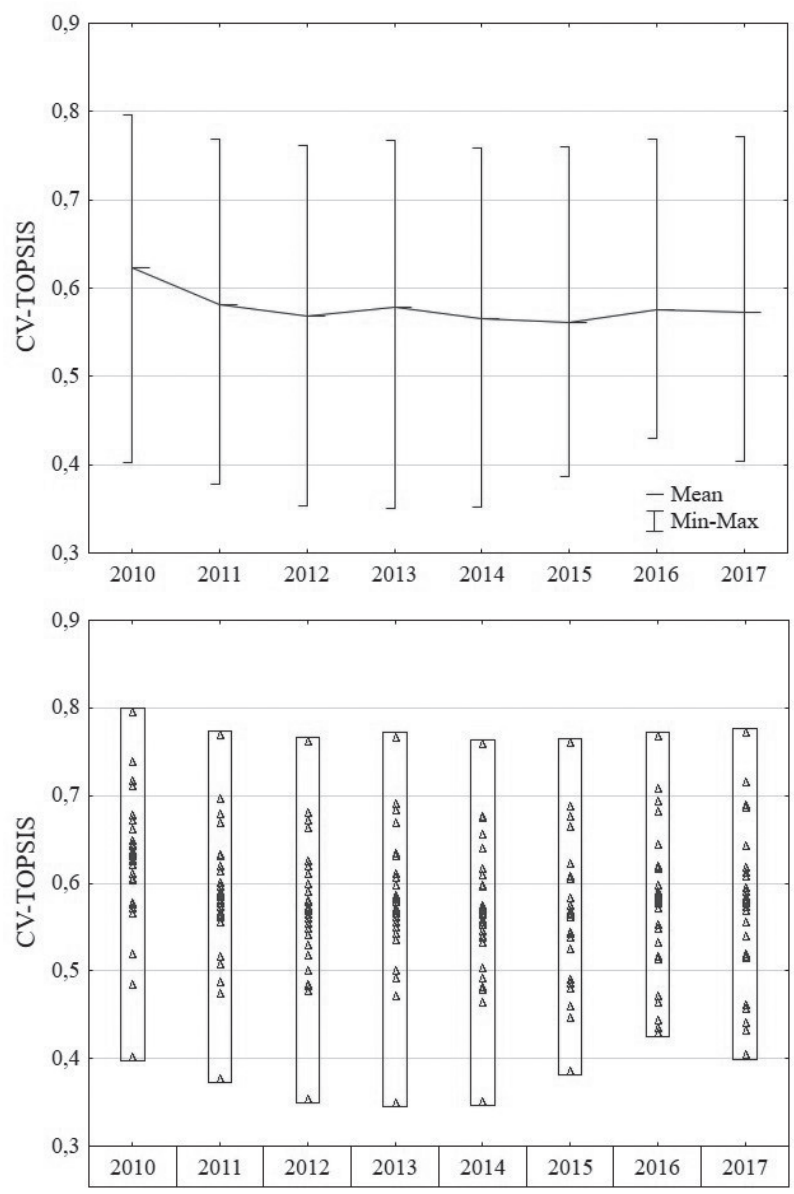

Fig. 2. Overall results of multi-criteria evaluation of EU countries (2010-2017). the best- and worst-rated countries are then identified, and their comparison is the subject of the next part of the analysis. In order to generalize the conclusions thus obtained, they are confronted in the last step with the development of the monitored indicators in other EU countries.

\section{Evaluation of the Results of Multi-Criteria Analysis}

In the first step, the set of 28 EU countries is evaluated on the basis of a set of 8 indicators and the CV-TOPSIS method. The results are depicted in Fig. 2, by means of which we illustrate not only the structure but also the properties of the results (their moment characteristics) in individual years of the analyzed period, which are significant for further processing of the analysis.

The variation range of the results in the first five years did not change significantly; its significant reduction (by 9.44\%) and thus a reduction of the differences between countries, can be observed only in 2016. Despite this change, we can observe homoscedasticity of the overall results $(\mathrm{LE}=0.161$; $p=0.992)$ and thus the match of their variance. With respect to the confirmed normality of the results by the Shapiro-Wilk test (at the significance level $\alpha=0.05$ ), the difference in mean values $(F=1.61 ; p=0.134)$ was not confirmed. However, the difference was reflected in the median $(\mathrm{Q}=16.81 ; \mathrm{p}=0.186)$, which is attributed to a gradual change in the slope and concentration of the results around the mean, i.e. a change in their kurtosis. Based on the above results, it can be stated that there are no significant deviations in the overall development of the monitored indicators over time. There are changes within the individual indicators (positive and negative, incremental and major), but these changes do not ultimately appear to be essential to the overall results of the multi-criteria evaluation (Fig. 3).

Differences in the results of the 8 monitored indicators persist across the period under review, with an overall positive change in the development of the results of the multi-criteria evaluation, over

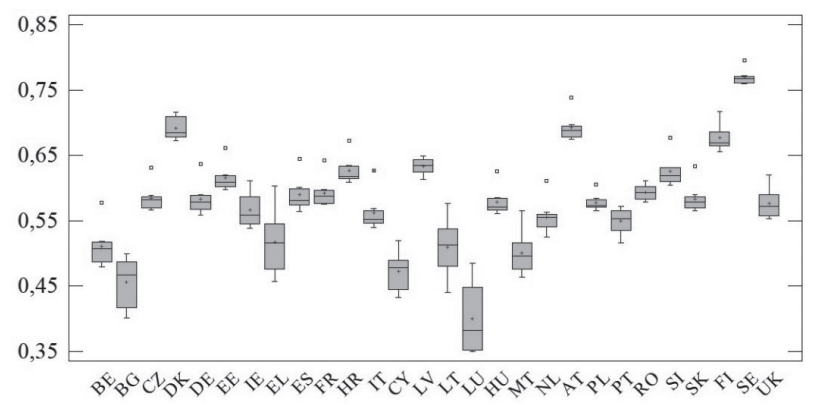

Fig. 3. Overall results of multi-criteria evaluation from the perspective of individual countries (2010-2017). 


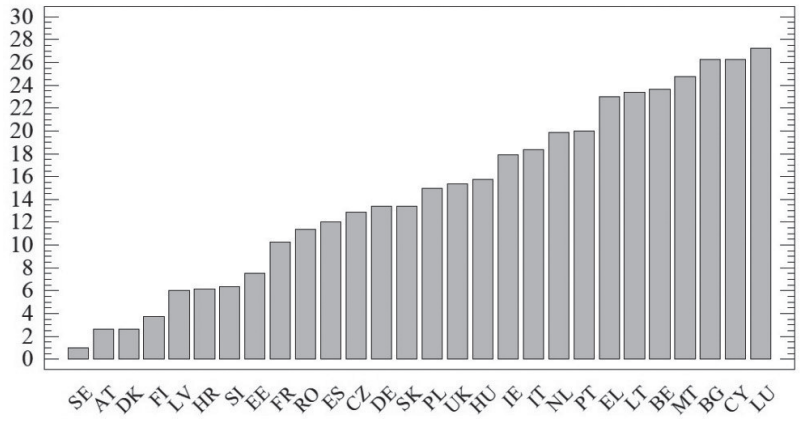

Fig. 4. Average position on the basis of multi-criteria evaluation from the perspective of individual countries (2010-2017).

the 8 years under review, occurring only in Bulgaria $(0.55 \%)$ and Denmark $(0.66 \%)$. Given the magnitude of these changes, however, we can speak of keeping up the rate rather than an improvement in ranking. However, in the context of the development in other countries, it is not possible to work solely with absolute values; therefore Fig. 4 shows the average position

of EU countries for the whole period under review.

The overall assessment of Sweden fell by $2.98 \%$ over the 8 years under review, but this did not represent a change in the country's position, which was always rated as the best. On the other side of the spectrum was Luxembourg, whose improvement over the last 4 years was not sufficient, and its average score was therefore the worst $\left(\bar{x}_{L U}=28.25\right)$. It is these two countries that have served as a benchmark for further analysis to identify the causes of such a balanced assessment, and to recommend areas for further improvement at the level of particular EU countries.

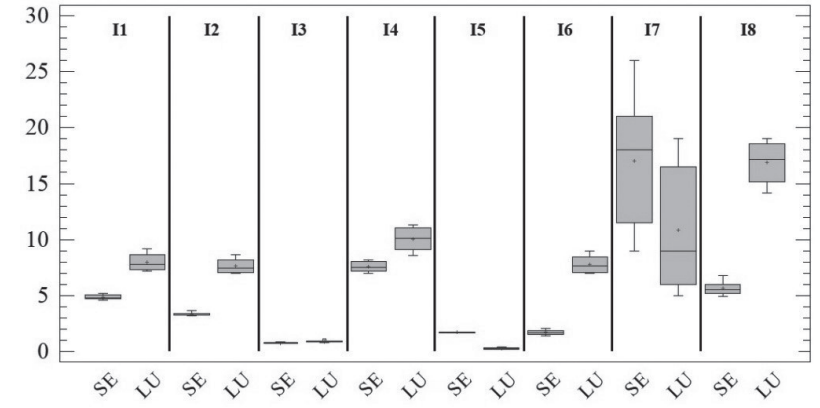

Fig. 6. Differences in the level of monitored indicators between Sweden and Luxembourg during the studied period 2010-2017.

The Results of the Multi-Criteria Evaluation in the Context of the Monitored Indicators

After analysing the overall results, we discussed in the previous section, we consider it necessary to identify the relationship of these results to the individual indicators. Thus, in the first phase, we focus on identifying the sequence correlation, captured in Fig. 5.

From the perspective of the outlined results, we can divide the 8 indicators into three groups. The first group could be described as a group of indicators with a unique explanatory power, whose growth or decline did not affect the overall results of our assessment. This group includes Primary energy consumption (I1) and Energy productivity (I4). The second group consists of indicators whose significant relationship with the overall results is not stable during the whole evaluated period. This group includes Total energy consumption (I2), Energy dependence (I6) and Greenhouse gas emissions (I8). The third group of indicators shows a significant

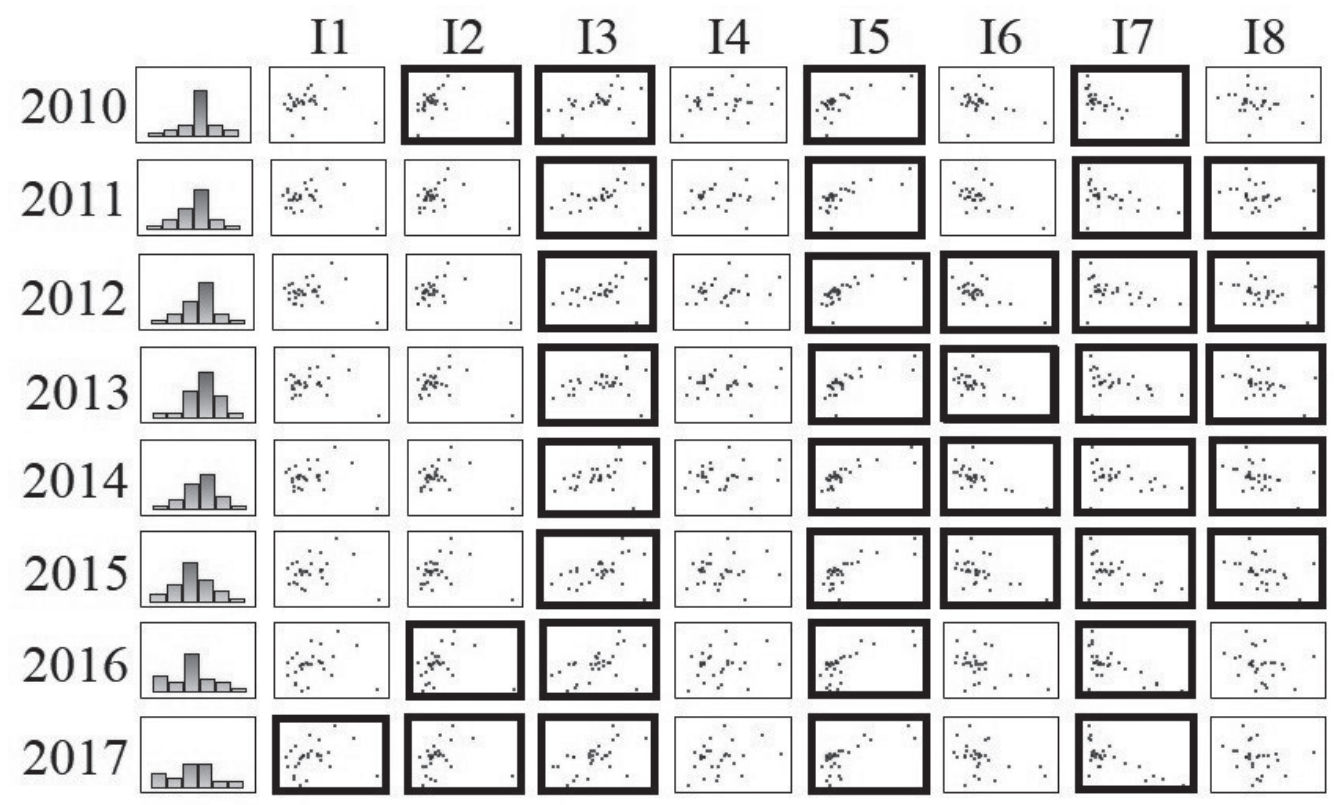

Fig. 5. Relationship between overall results of multi-criteria evaluation and individual indicators. 
Table 2. Strength of identified sequence correlation of overall results of multi-criteria evaluation and individual indicators (2010-2017).

\begin{tabular}{|c|c|c|c|c|c|c|c|c|}
\hline & I1 & I2 & I3 & I4 & I5 & I6 & I7 & I8 \\
\hline $\mathbf{2 0 1 0}$ & MIN & MIN & MIN & MAX & MAX & MIN & MIN & MIN \\
\hline $\mathbf{2 0 1 1}$ & & 0.29 & 0.35 & & 0.58 & & -0.46 & \\
\hline $\mathbf{2 0 1 2}$ & & & 0.34 & & 0.54 & & -0.43 & -0.28 \\
\hline $\mathbf{2 0 1 3}$ & & & 0.34 & & 0.60 & -0.29 & -0.36 & -0.31 \\
\hline $\mathbf{2 0 1 4}$ & & & 0.28 & & 0.54 & -0.30 & -0.38 & -0.32 \\
\hline $\mathbf{2 0 1 5}$ & & & 0.37 & & 0.51 & -0.33 & -0.34 & -0.33 \\
\hline $\mathbf{2 0 1 6}$ & & 0.28 & 0.41 & & 0.51 & -0.38 & -0.37 & -0.33 \\
\hline $\mathbf{2 0 1 7}$ & 0.28 & 0.33 & 0.34 & & 0.49 & & -0.43 & \\
\hline
\end{tabular}

Note: values represent confirmed correlation calculated using Kendall coefficient at observed significance level $\alpha=0.05$

relationship with the fulfilment rate of SDG 7 in the form of multi-criteria assessment over the whole period. This group includes three indicators: Final consumption in households per capita (I3), Production of renewable energy (I5), and Population unable to keep home adequately warm by poverty status (I7).
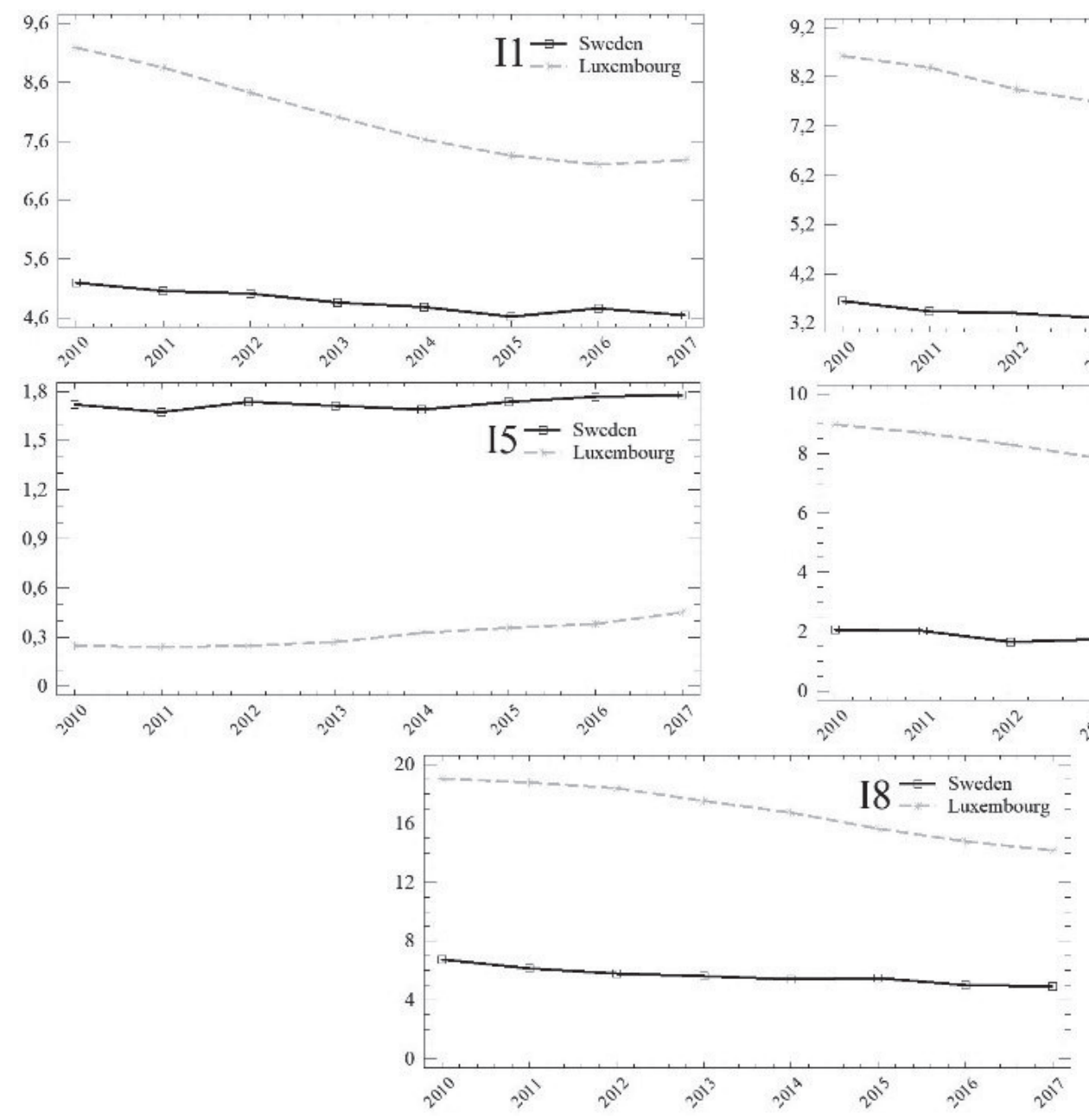

Fig. 7. Development of indicators I1, I2, I5, I6 and I8 in Sweden and Luxembourg (2010-2017).
With improving overall results, we can expect better values of Households at risk of poverty (I7) and partially also Energy dependence (I6), Greenhouse gas emissions (I8) or Share of renewable energy (I5). By contrast, the assessment of Household consumption (I3) decreases with the overall assessment of individual

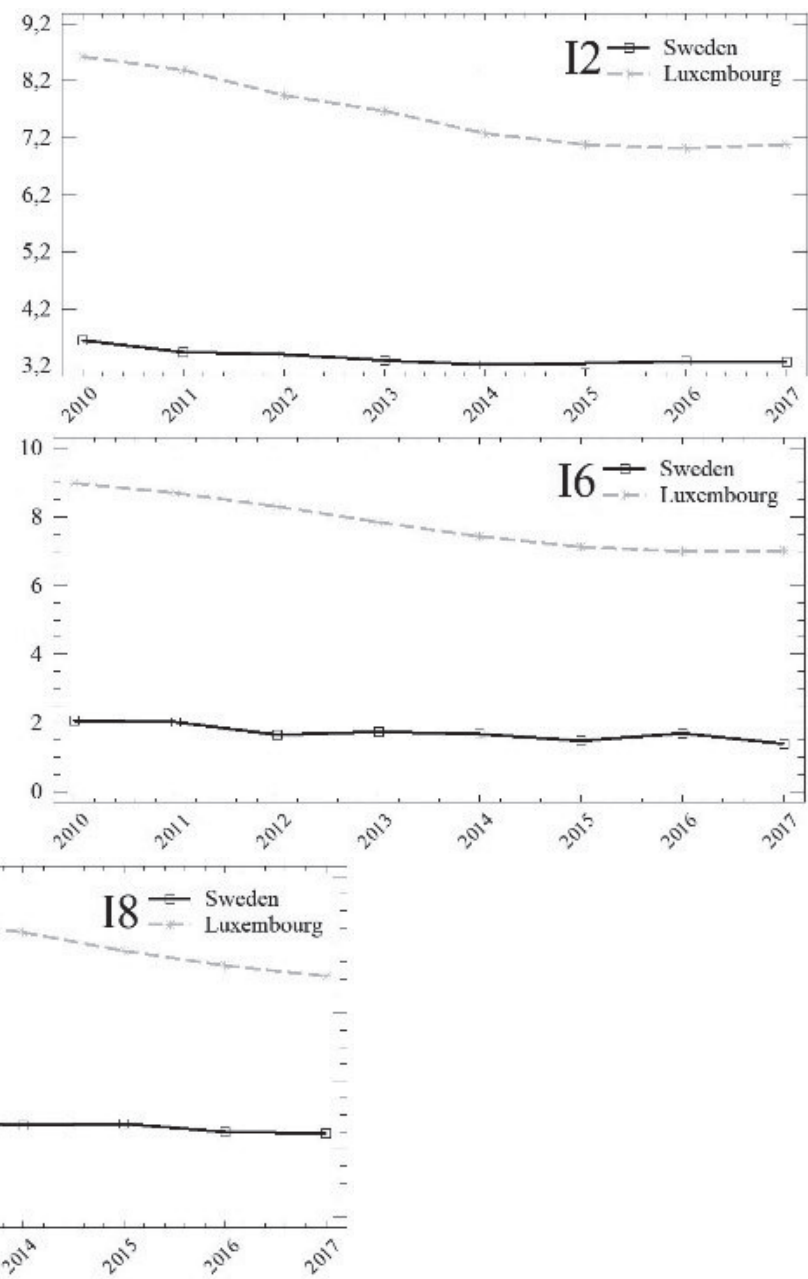




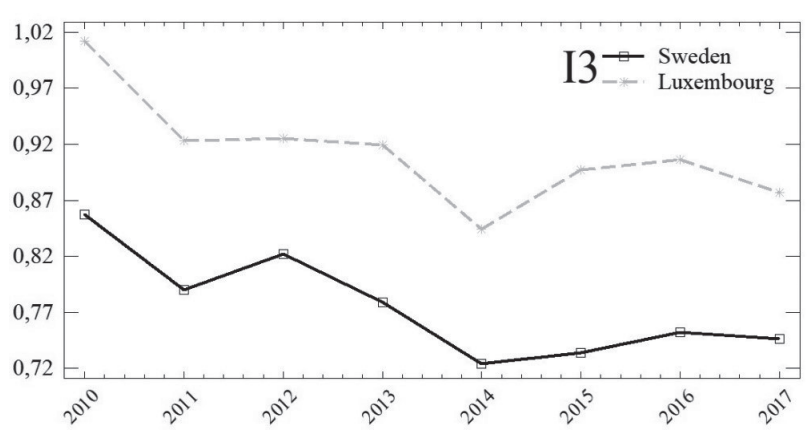

Fig. 8. Development of I3 indicator in Sweden and Luxembourg (2010-2017).

countries. This may confirm the existence of a rebound effect or Jevon paradox, stating that rising energy consumption can reduce the expected gains from new energy-efficient technologies, or increase the share of renewables. A similar conclusion was reached by $[63,64]$, and others. Although the determination of the magnitude of the rebound effect is not the subject of this study, we suggest paying attention to effective policy measures and incentives to promote energy savings at the household level. This supports the findings of [65] that energy policy measures adopted in EU countries focusing on household sector lack the expected efficiency. In all cases, we can observe a low or middle rank correlation, which supports the application of multi-criteria evaluation. This approach creates new and added value in the context of energy sustainability assessment, as it does not follow the
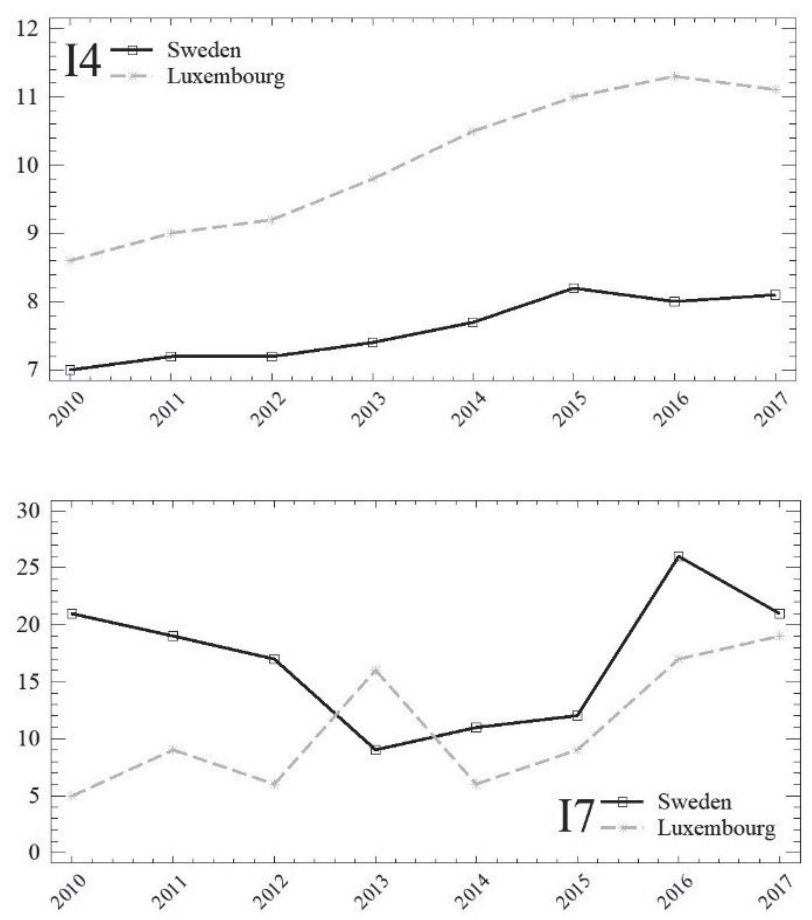

Fig. 9. Development of indicators I4, I7 in Sweden and Luxembourg (2010-2017). evolution of individual indicators at the individual level, but rather takes into account the interrelationships and interconnections between these indicators.

\section{Differences in the Assessment of the Level of Indicators in 'Benchmark Countries'}

Differences persisting over the whole reporting period were shown to be statistically significant and constant, which allowed the countries located at both ends of the evaluation spectrum to be selected. These countries were Sweden, as the best-ranking country, and Luxembourg, as the worst-ranking country among the 28 EU countries. We assume that these results conceal one or more indicators, which we analyse in this section (Fig. 6).

The prevalence of the best-placed country (Sweden) is mainly observed in the case of indicators I1, I2, I5, I6 and I8. In the case of Household consumption (I3), these differences are significantly smaller; even with two indicators (I4 - Energy productivity, I7 - Households at risk of poverty), Luxembourg shows better values.
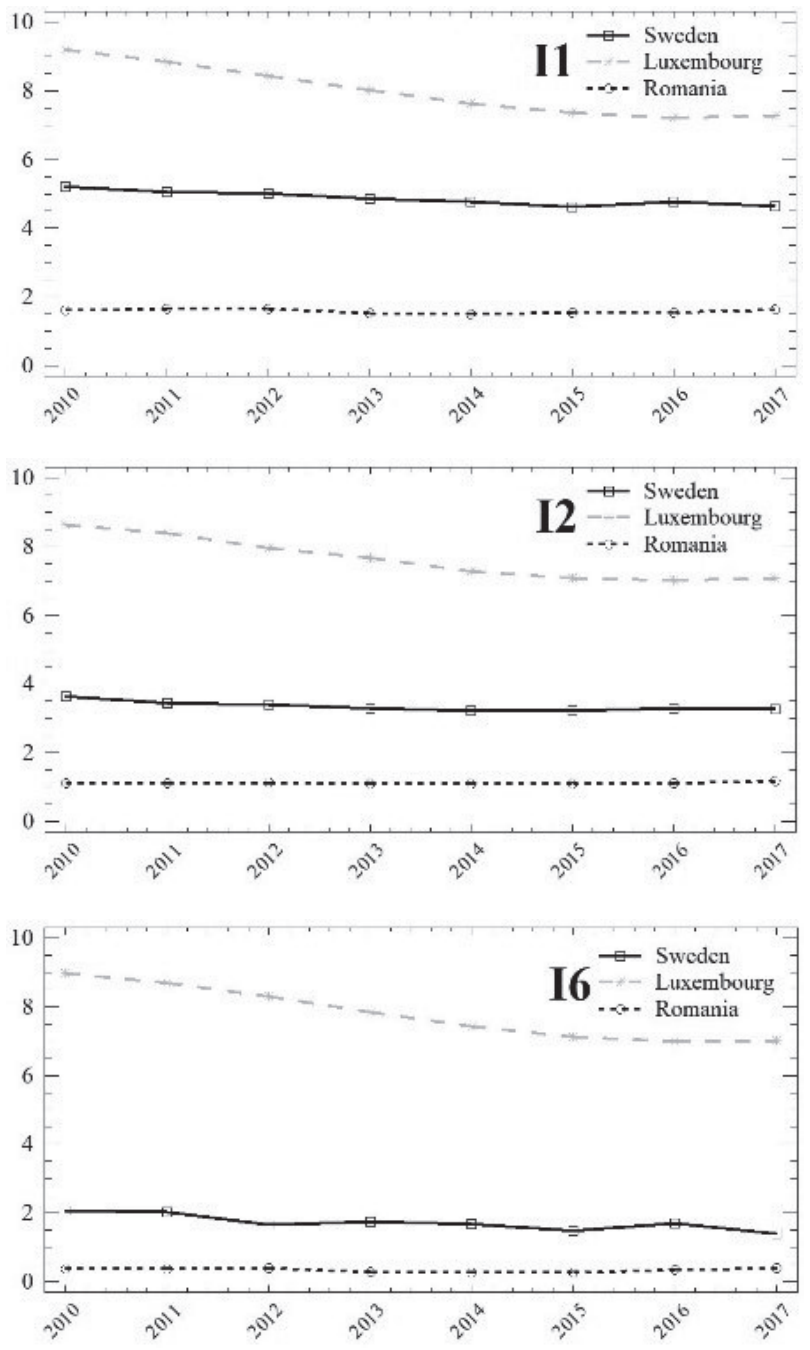

Fig. 10. Luxembourg as the worst rated country by indicators I1, I2, I6 (2010-2017). 


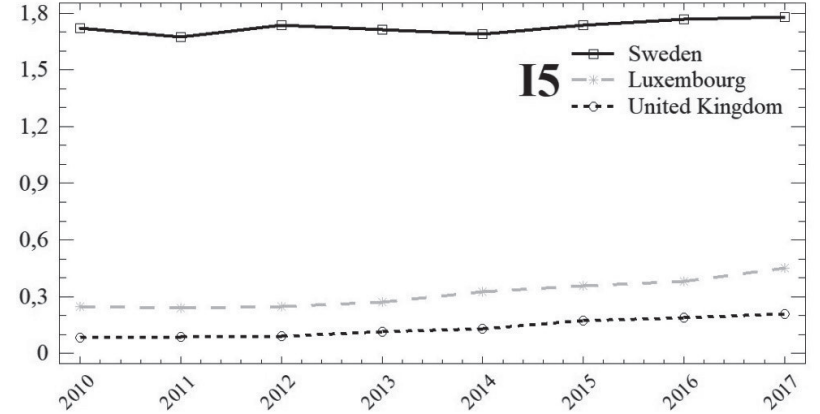

Fig. 11. Sweden as the highest rated country by I5 indicator (2010-2017).

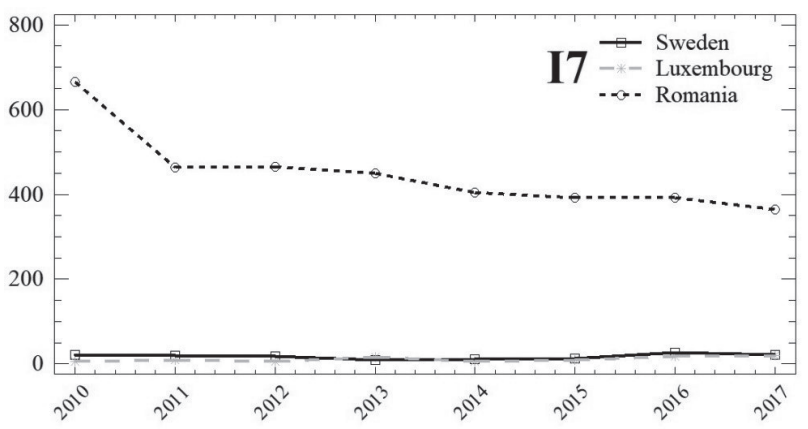

Fig. 12. Luxembourg as the best rated country by I7 indicator (2010-2017)

This division of indicators demonstrates that each country has strengths and weaknesses that need to be addressed in the future (Table 2).

Sweden's dominance in Energy consumption (I1), Total energy consumption (I2) and Share of renewable energy (I5) is accompanied by a balance of these results, documented by a coefficient of variation not exceeding $4.25 \%$. This indicator level can therefore be described as characteristic of this country. From the Luxembourg point of view, however, the higher variability $\left(\mathrm{v}_{\mathrm{LU}}>8.20 \%\right)$ does not, in our opinion, make it possible to mark the level of some of the indicators as typical, or characteristic for this country (Fig. 7).

For Household consumption (I3), the relative difference between Sweden and Luxembourg is lower than for the previous set of indicators. However, despite the slightly higher variability $\left(\mathrm{v}_{\mathrm{SE}}=5,93 \%\right.$; $\mathrm{V}_{\mathrm{LU}}=5,3 \%$ ), differences among countries persist and are not expected to decrease (Fig. 8).

The most interesting results in the comparison of the two countries can be seen when comparing the results of Energy productivity (I4) and Households at risk of poverty (I7), see Fig. 9. In the evaluation of the first one, Luxembourg achieves better values, which in the course of time increase in absolute terms by an increase in both countries. The second evaluated indicator (I7) shows the biggest year-on-year difference, and thus the highest variability of results. From the point of
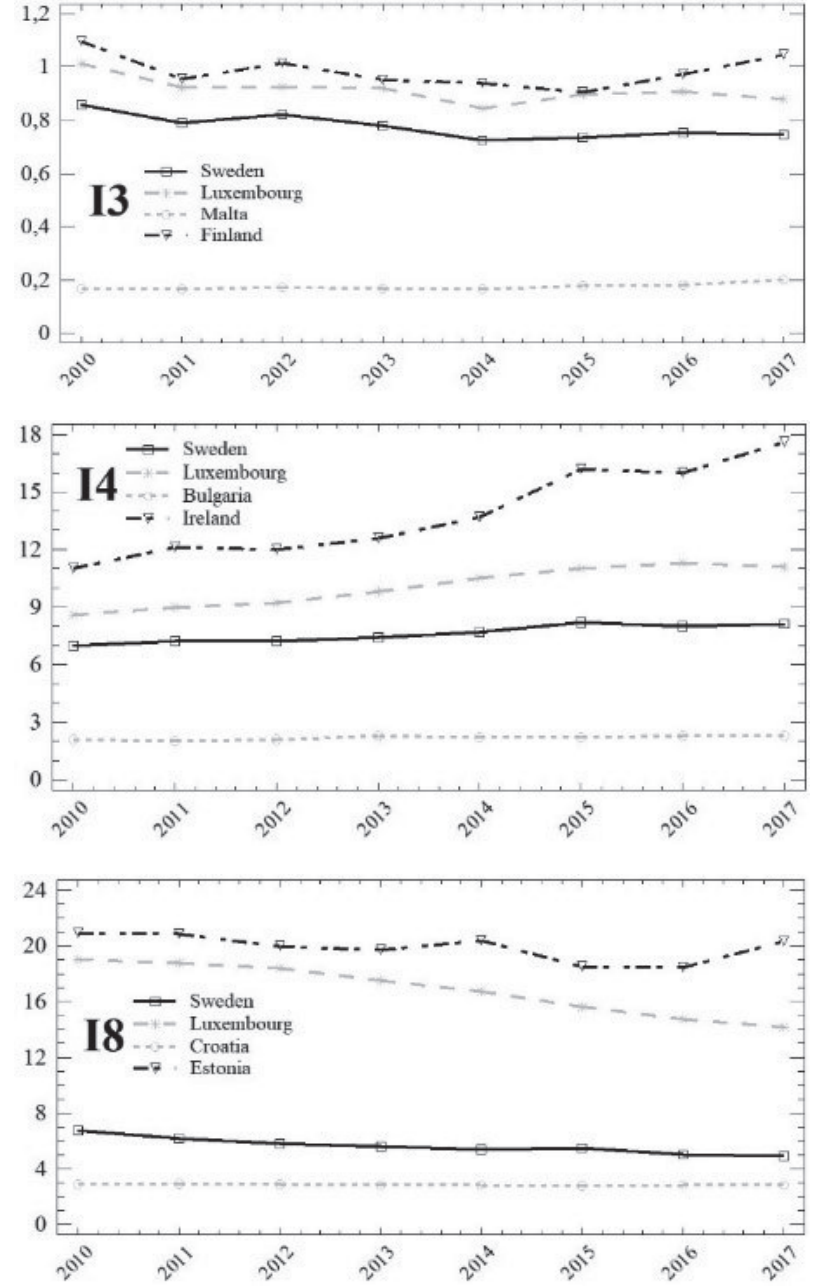

Fig. 13. Evaluation of Sweden and Luxembourg in the context of other EU countries by indicators I3, I4, I8 (2010-2017).

view of this indicator, it is not possible to conclude the dominance of one country or another.

\section{Verification of Results by Comparison of Indicators in All Countries}

In the previous section, we identified indicators, or the level of indicators, that should be characteristic for Sweden or Luxembourg as countries with a stable position in the multi-criteria evaluation of EU countries. Within this section, these results are verified against those achieved in other countries under review, with the aim of identifying leaders in each area/ indicator.

In the case of Luxembourg, we see the greatest weaknesses in the three indicators in which this country was rated as the worst. These indicators refer to Primary energy consumption per capita (I1), Final energy consumption per capita (I2) and Energy import dependency (I6). Romania performs best in all three indicators (see Fig. 10), with Sweden ranking among the worst-performing countries. This result also indicates disparities in living standards among countries. 
We observe the opposite situation with regards to the share of renewable energy (I5) in the case of Sweden, which, together with Finland, can be considered a leader across EU countries. The biggest deficiencies are observed in island countries, such as Cyprus, Ireland, or the United Kingdom (see Fig. 11). Reasons vary from country to country, and include level of economic development as well as geographical and natural circumstances, but also political preferences and social factors, such as NIMTOO (not in my term of office) or NIMBY (not in my back yard) effect [66].

Paradoxically, when assessing Households at risk of poverty (I7) (Fig. 12), Luxembourg performs as the overall best-rated country. In absolute terms, however, we cannot speak of dominance, as Finland and Sweden placed closely behind, with a minimum distance. The maturity of the economy and the high standard of living of the population can be identified as the main reasons for placing these countries at the top of the list.

From the perspective of other indicators, the development of which is shown in Fig. 13, Sweden and Luxembourg achieve an average rating, compared to the results of other countries. We can perceive Sweden more negatively; for that country, these results are a weakness, in the context of the other countries, that needs to be addressed. Conversely, the results of Energy productivity (I4) can be described as Luxembourg's strength.

Shift within the eight energy-related indicators in Sweden and Luxembourg over the monitored period is shown in Fig. 14.

\section{Conclusions}

The multi-criteria evaluation of EU countries was carried out using the TOPSIS technique in combination

2010

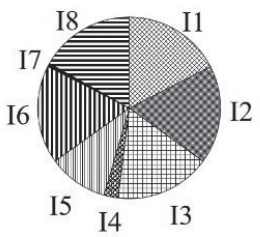

2017

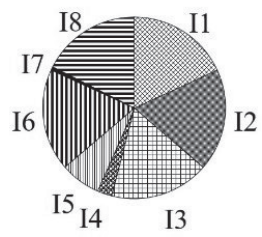

Luxembourg
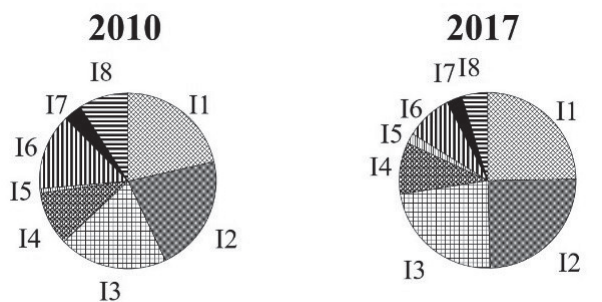

Sweden

Fig. 14. Strengths and weaknesses of Luxembourg and Sweden in SDG7 indicators (2010 vs 2017). with the $\mathrm{CV}$ technique as an objective method for determining the importance of the input 8 energy indicators, monitored by the EU statistical office. A total of 8 years were evaluated (2010-2017), and this assessment can be described as balanced and stable with a slight but gradual change in skewness. The high informative value was supported by monitoring the sequence correlation between individual indicators. Based on the results obtained, Sweden was identified as the best-rated country, one which has long dominated our multi-criteria assessment of SDG 7. Compared to the worst-rated country (Luxembourg), it was characterized by stable results in the assessment of the three indicators: Primary energy consumption per capita (I1), Final energy consumption per capita (I2) and Production of renewable energy (I5), but lagged significantly in the assessment of Energy productivity (I4). However, the subsequent comparison with other countries showed that even the dominant country achieved significantly negative results in some indicators over the long term. This includes the abovementioned Primary energy consumption per capita (I1) and Final energy consumption per capita (2).

To identify the shortcomings of the two countries, we have withdrawn from absolute values and replaced them with an ordinal variable, i.e. ranking among the 28 countries evaluated. Luxembourg's problem is the five indicators in which the country is rated as worst. These indicators include Primary energy consumption per capita (I1), Final energy consumption per capita (I2), Final energy consumption in households (I3), Energy import dependency (I6) and Total GHG emissions (I8). Romania, which is among the best in these indicators, can serve as an inspiration. On the other hand, Luxembourg could be a model for other countries in the area of Population unable to keep home adequately warm by poverty status (I7). Sweden is among the worst in the first three indicators (I1, I2, I3). These deficiencies are mainly offset by Share of renewable energy (I5), in which, together with Finland, they dominate significantly.

On the basis of the results obtained, we do not consider Sweden to be the best country in the context of the SDG 7. Its problem is the focus on one area (renewables), which compensates for weaker, or weak, results in other directions. Likewise, Luxembourg cannot be regarded as a "loser", as in some respects it could be seen as a model for other countries. The issue of assessing SDGs is difficult and complicated. However, we can say with certainty that the comprehensive fulfilment of the monitored indicators has not been recorded in any country. The reason can be found in the specifics of individual countries (geographical, cultural) or in the political priorities of individual governments. A focus on one area/indicator is accompanied by a neglect of other sustainable energy issues.

In view of the complexity of sustainable development assessment, it is important, in our view, to address all the monitored indicators of SDG 7, not 
just selected ones. Although Sweden achieved the best and most stable results during the period under review, this occurred despite the shortcomings in indicators I1, I2, I3. The question remains whether such heterogeneity at the level of individual indicators is desirable or not; whether it is not more sustainable to choose the path taken, for example, by Spain or Portugal, i.e. countries that did not achieve the best or the worst values in any of the monitored indicators. Finding the right alignment of EU priorities with respect to its member states, in all the monitored indicators, could be a means of long-term sustainability.

The CV-TOPSIS method allowed us to perform a rather comprehensive analysis of the state of fulfilment of SDG 7 in EU countries. However, due to the complexity of sustainable development assessment, it is necessary to think out of the energy box, and take into account interactions with other sustainable development goals [67], which can be both positive and negative. However, in addition to the interdependence of various sustainable development goals, a comprehensive approach to their implementation also plays an important role, as [68] pointed out; this takes into account, for example, pressure behind some sustainability issues or responses, or pressure on policy and decision-makers, to put targets into practice.

The presented results form the basis and open up opportunities for further research in the field of sustainable development. Several authors [69, 70] declare a strong interdependence of energy sustainability and other priority areas of sustainable development, e.g. food safety and water quality (so-called water-energy-food nexus). However [71, 72] also point to the much broader link between energy sustainability and other SDGs. Therefore, exploring the interconnection and synergies between energy and other sustainable development goals opens up possible ways for future research.

\section{Acknowledgments}

This work was supported by the Scientific Grant Agency of the Ministry of Education, Science, Research and Sport of the Slovak Republic and the Slovak Academy of Sciences (1/0508/21), and the Student Grant Competition in VŠB -Technical University of Ostrava (SP2022/29).

\section{Conflict of Interest}

The authors declare no conflict of interest.

\section{References}

1. BENSON D., RUSSEL D. Patterns of EU Energy Policy Outputs: Incrementalism or Punctuated Equilibrium? West European Politics, 38 (1), 185, 2015.
2. CHOVANCOVÁ J., VAVREK R. (De)coupling Analysis with Focus on Energy Consumption in EU Countries and Its Spatial Evaluation. Polish Journal of Environmental Studies, 29 (2), 1, 2020.

3. CHOVANCOVÁ J., VAVREK R. Energy Performance of the European Union Countries in Terms of Reaching the European Energy Union Objectives. Energies, 13 (20), 5317, 2020.

4. TAGLIAPIETRA S., ZACHMANN G., EDENHOFER O., GLACHANT J.M., LINARES P., LOESCHEL A. The European union energy transition: Key priorities for the next five years. Energy Policy, 132, 950, 2019.

5. The European Environment: State and Outlook 2020: Synthesis. In European Environment Agency. Available online: https://www.eea.europa.eu/publications/soer-2020 (accessed on $01^{\text {st }}$ March 2021).

6. Communication from the Commission to the European Parliament, the European Council, the Council, the European Economic and Social Committee, the Committee of the Regions and the European Investment Bank - A clean planet for all: a European strategic long- term vision for a prosperous, modern, competitive and climate neutral economy. Available online: https:/eur-lex.europa.eu/ legal-content/en/TXT/?uri=CELEX\%3A52018DC0773 (accessed on $20^{\text {th }}$ February 2021).

7. The 2030 agenda for sustainable development. Available online: https://sustainabledevelopment.un.org/post2015/ transformingourworld/publication (accessed on 27 $7^{\text {th }}$ February 2021).

8. Transforming our world: the 2030 Agenda for Sustainable Development. Available online: https://sustainabledevelopment.un.org/content/ documents $/ 21252030 \% 20$ A genda\% 20 for \% 20 Sustainable\%20Development\%20web.pdf (accessed on $16^{\text {th }}$ February 2021).

9. Advocacy Toolkit Influencing the Post-2015 Development Agenda. Available online: http://www.stakeholderforum. org/fileadmin/files/Post2015AdvocacyToolkit.pdf (accessed on $15^{\text {th }}$ February 2021).

10. Report of the World Commission on Environment and Development. Our Common Future. Available online: https://www.un.org/ga/search/view_doc. asp?symbol $=\mathrm{A} / 42 / 427 \&$ Lang $=\mathrm{E}$ (accessed on $15^{\text {th }}$ February 2021).

11. Brundtland Report: A 20 Years Update. Keynote Speech presented at the European Sustainability: Linking Policies, Implementation, and Civil Society Action conference. Available online: https://www.sd-network.eu/ pdf/conferences/2007_berlin/ESB07_Plenary_Hauff.pdf (accessed 05 March 2021).

12. Review of implementation of Agenda 21 and the Rio Principles. Available online: https:// sustainabledevelopment.un.org/content/ documents/641Synthesis_report_Web.pdf (acessed on 02nd March 2021).

13. Summary for Policymakers. Available online: https:// www.cambridge.org/core/books/climate-change-2013-thephysical-science-basis/summary-for-policymakers/356E $277 \mathrm{FD} 1 \mathrm{FBC} 887845 \mathrm{FB} 9 \mathrm{E} 8 \mathrm{CBC} 90 \mathrm{CCD}$ (accessed on $07^{\text {th }}$ March 2021).

14. Rio Declaration on Environment and Development. Available online: https://www.cambridge.org/core/ services/aop-cambridge-core/content/view/47044FF6305 FAFD44BA9EBE3C3072097/S037689290003157Xa.pdf/ rio_declaration_on_environment_and_development.pdf (accessed on $15^{\text {th }}$ February 2021). 
15. SACHS J., MCARTHUR J. The Millennium Project: a plan for meeting the Millennium Development Goals. The Lancet, 365 (9456), 347, 2005.

16. SCHMIDT-TRAUB, G., KROLL, C., TEKSOZ, K., DURAND-DELACRE, D., SACHS, J. D. National baselines for the Sustainable Development Goals assessed in the SDG Index and Dashboards. Nature Geoscience, 10, 547-555, 2017.

17. SACHS, J. D. The Age of Sustainable Development. The Age of Sustainable Development; Columbia University Press: New York, USA, 2016.

18. STAFFORD-SMITH, M., GRIGGS, D., GAFFNEY, O., ULLAH, F., REYERS, B., KANIE, N., STIGSON, B., SHRIVASTAVA, P., LEACH, M., O'CONNELL, D. Integration: the key to implementing the Sustainable Development Goals. Sustainability Science, 12, 911, 2017.

19. BREW-HAMMOND. Energy: The Missing Millennium Development Goal. In Toth, F.L. (Ed.), Springer: Dordrecht, England, 35, 212.

20. GORE C. The Post-2015 Moment: Towards Sustainable Development Goals and a New Global Development Paradigm. Journal of International Development, 27 (6), 717, 2015.

21. LE BLANC D. The sustainable development goals as a network of targets. Monitoring and Evaluation NEWS. Department of Economic and Social Affairs, 1 (141), 1, 2015.

22. TOSUN J., LEININGER J. Governing the Interlinkages between the Sustainable Development Goals: Approaches to Attain Policy Integration. Global Challenges, 1 (9), 1700036, 2017.

23. LU Y., NAKICENOVIC N., VISBECK M., STEVANCE A.S. Policy: Five priorities for the on Sustainable Development Goals. Nature, 520 (7548), 432, 2015.

24. FUSO NERINI F., TOMEI J., TO L.S., BISAGA I., PARIKH P., BLACK M., BORRION A., SPATARU C., CASTÁN BROTO V., ANANDARAJAH G., MILLIGAN B., MULUGETTA Y. Mapping synergies and trade-offs between energy and the Sustainable Development Goals. Nature Energy, 3, 10, 2018.

25. NILSSON M., GRIGGS D., VISBECK M. Policy: Map the interactions between Sustainable Development Goals. Nature, 534, 320-322, 2016.

26. WEITZ, N., CARLSEN, H., NILSSON, M., SKÅNBERG, $\mathrm{K}$. Towards systemic and contextual priority setting for implementing the 2030 agenda. Sustainability Science, 13, 531, 2018.

27. GIUPPONI C., GAIN A.K. Integrated spatial assessment of the water, energy and food dimensions of the Sustainable Development Goals. Regional Environmental Change, 17, 1881, 2017.

28. VAVREK R., CHOVANCOVÁ J. Assessment of economic and environmental energy performance of EU countries using CV-TOPSIS technique. Ecological Indicators, 106, 105519, 2019.

29. COSTANZA R., DALY L., FIORAMONTI L., GIOVANNINI E., KUBISZEWSKI I., MORTENSEN L.F., PICKETT K.E., RAGNARSDOTTIR K.V., DE VOGLI R., WILKINSON R. Modelling and measuring sustainable wellbeing in connection with the UN Sustainable Development Goals. Ecological Economics, 130, 350, 2016.

30. RÖSCH C., BRÄUTIGAM K.R., KOPFMÜLLER J., STELZER V., LICHTNER P. Indicator system for the sustainability assessment of the German energy system and its transition. Energy, Sustainability and Society, 7, 1
(2017), 2017.

31. BELL S., MORSE S. Sustainability Indicators: Measuring the Immeasurable? Routledge: Abingdon, England, 2012.

32. JOLLANDS N. How to aggregate sustainable development indicators: A proposed framework and its application. International Journal of Agricultural Resources, Governance and Ecology, 5 (1), 18, 2006.

33. SANTOYO-CASTELAZO E., AZAPAGIC A. Sustainability assessment of energy systems: Integrating environmental, economic and social aspects. Journal of Cleaner Production, 80, 119, 2014.

34. ZAVADSKAS E.K., MARDANI A., TURSKIS Z., JUSOH A., NOR K.M. Development of TOPSIS Method to Solve Complicated Decision-Making Problems - An Overview on Developments from 2000 to 2015. International Journal of Information Technology and Decision Making, 15 (3), 645, 2016.

35. TRAMARICO C.L., MIZUNO D., SALOMON V.A.P., MARINS F.A.S. Analytic hierarchy process and supply chain management: A bibliometric study. Procedia Computer Science, 55, 441, 2015.

36. VAVREK R. Evaluation of the Impact of Selected Weighting Methods on the Results of the TOPSIS Technique. International Journal of Information Technology \& Decision Making, 18 (6), 1821, 2019.

37. ROZENTALE L., BLUMBERGA D. Methods to Evaluate Electricity Policy from Climate Perspective. Environmental and Climate Technologies, 23 (2), 131, 2019.

38. POLIKARPOVA I., LAUKA D., BLUMBERGA D., VIGANTS E. Multi-Criteria Analysis to Select Renewable Energy Solution for District Heating System. Environmental and Climate Technologies, 23 (3), 101, 2019.

39. SIKSNELYTE I., ZAVADSKAS E.K., BAUSYS R., STREIMIKIENE D. Implementation of EU energy policy priorities in the Baltic Sea Region countries: Sustainability assessment based on neutrosophic MULTIMOORA method. Energy Policy, 125, 90, 2019.

40. SUHAREVSKA K., BLUMBERGA D. Progress in Renewable Energy Technologies: Innovation Potential in Latvia. Environmental and Climate Technologies, 23 (2), 47, 2019.

41. SIKSNELYTE I., ZAVADSKAS E.K. Achievements of the European Union countries in seeking a sustainable electricity sector. Energies, 12 (11), 1, 2019.

42. YUAN J., LUO X. Regional energy security performance evaluation in China using MTGS and SPA-TOPSIS. Science of the Total Environment, 696, 133817, 2019.

43. WANG D., SHI Y., WAN K. Integrated evaluation of the carrying capacities of mineral resource-based cities considering synergy between subsystems. Ecological Indicators, 108, 105701, 2020.

44. INDZERE Z., MELVERE M., MUIZNIECE I., BLUMBERGA D. The Evaluation of Factors Affecting Bioeconomy Development Using Transdisciplinary Approach. Environmental and Climate Technologies, 23 (3), 360, 2019.

45. DIAZ F., CILINSKIS E. Use of Multi-Criteria TOPSIS Analysis to Define a Decarbonization Path in Colombia. Environmental and Climate Technologies, 23 (2), 110, 2019.

46. PAUL S., SARKAR B. An exploratory analysis of biofuel under the utopian environment. Fuel, 262, 116508, 2020.

47. LIU J., YIN Y. An integrated method for sustainable energy storing node optimization selection in China. Energy Conversion and Management, 1991, 112049, 2019. 
48. ZHANG L., ZHANG L., XU Y., ZHOU P., YEH C.H. Evaluating urban land use efficiency with interacting criteria: An empirical study of cities in Jiangsu China. Land Use Policy, 90, 104292, 2020.

49. ZHU S., LI D., FENG H. Is smart city resilient? Evidence from China. Sustainable Cities and Society, 50, 101636, 2019.

50. DJORDJEVIĆ B., KRMAC E. Evaluation of energyenvironment efficiency of European transport sectors: Non-radial DEA and TOPSIS approach. Energies, 12 (15), 2907, 2019.

51. LUAN B., YIN R., XU P., WANG X., YANG X., ZHANG L., TANG X. Evaluating Green Stormwater Infrastructure strategies efficiencies in a rapidly urbanizing catchment using SWMM-based TOPSIS. Journal of Cleaner Production, 223, 680, 2019.

52. MA L., LONG H., CHEN K., TU S., ZHANG Y., LIAO L. Green growth efficiency of Chinese cities and its spatiotemporal pattern. Resources, Conservation and Recycling, 146, 441, 2019.

53. WU Y., XU C., ZHANG B., TAO Y., LI X., CHU H., LIU F. Sustainability performance assessment of wind power coupling hydrogen storage projects using a hybrid evaluation technique based on interval type-2 fuzzy set. Energy, 179, 1176, 2019.

54. SEYEDMOHAMMADI J., SARMADIAN F., JAFARZADEH A.A., GHORBANI M.A., SHAHBAZI F., 2018. Application of SAW, TOPSIS and fuzzy TOPSIS models in cultivation priority planning for maize, rapeseed and soybean crops. Geoderma, 310, 178, 2017.

55. CAMBAZOĞLU S., YAL G.P., EKER A.M., ŞEN O., AKGÜN H. Geothermal resource assessment of the Gediz Graben utilizing TOPSIS methodology. Geothermics, 80, 92, 2019.

56. OUERGHI H., MOURALI O., ZAGROUBA E. Nonsubsampled shearlet transform based MRI and PET brain image fusion using simplified pulse coupled neural network and weight local features in YIQ colour space. IET Image Processing, 12 (10), 1873, 2018.

57. GIRLING A. J. Relative efficiency of unequal cluster sizes in stepped wedge and other trial designs under longitudinal or cross-sectional sampling. Statistics in Medicine, 37 (30), 4652-4664, 2018.

58. SINGLA A., AHUJA I.S., SETHI A.S. Comparative Analysis of Technology Push Strategies influencing Sustainable Development in Manufacturing Industries using TOPSIS and VIKOR Technique. International Journal for Quality Research, 12 (1), 129, 2018.

59. SANGNAWAKIJ P., NIWITPONG S. Confidence intervals for coefficients of variation in two-parameter exponential distributions. Communications in Statistics: Simulation and Computation, 46 (8), 6618, 2017.

60. MUHAMMAD A.N.B., YEONG W.C., CHONG Z.L., LIM S.L., KHOO M.B.C. Monitoring the coefficient of variation using a variable sample size EWMA chart. Computers and Industrial Engineering, 126, 378, 2018.

61. TRAN K.P., HEUCHENNE C., BALAKRISHNAN N., On the performance of coefficient of variation charts in the presence of measurement errors. Quality and Reliability Engineering International, 35 (1), 329, 2019.

62. BHOWATE A., AWARE M., SHARMA S. Predictive Torque Control with Online Weighting Factor Computation Technique to Improve Performance of Induction Motor Drive in Low Speed Region. IEEE Access, 7, 42309, 2019.

63. BINSWANGER M. Technological progress and sustainable development: What about the rebound effect? Ecological Economics, 36 (1), 119, 2001.

64. LIN B., LIU X. Dilemma between economic development and energy conservation: Energy rebound effect in China. Energy, 45 (1), 867, 2012.

65. BERTOLDI P., MOSCONI R. Do energy efficiency policies save energy? A new approach based on energy policy indicators (in the EU Member States). Energy Policy, 139, 111320, 2020.

66. BELL D., GRAY T., HAGGETT C. The "social gap" in wind farm siting decisions: Explanations and policy responses. Environmental Politics, 14 (5), 460, 2005.

67. MCCOLLUM D.L., ECHEVERRI L.G., BUSCH S., PACHAURI S., PARKINSON S., ROGELJ J., KREY V., MINX J.C., NILSSON M., STEVANCE A.S., RIAHI K. Connecting the sustainable development goals by their energy inter-linkages. Environmental Research Letters, 3, 033006, 2018.

68. SPANGENBERG J.H. Hot Air or Comprehensive Progress? A Critical Assessment of the SDGs. Sustainable Development, 25 (4), 311, 2017.

69. FABIANI S., DALLA MARTA A., ORLANDINI S., CIMINO O., BONATI G., ALTOBELLI F. The WaterEnergy-Food Nexus in Europe. In: Water, Sustainable Development and the Nexus: Response to Climate Change; Grover, V. I., Alfarra, A., CRC Press: London, United Kingdom, 66, 2019.

70. YUAN M.H., LO S.L. Developing indicators for the monitoring of the sustainability of food, energy, and water. Renewable and Sustainable Energy Reviews, 119, 109565, 2020.

71. STAFFORD-SMITH M., GRIGGS D., GAFFNEY O., ULLAH F., REYERS B., KANIE N., STIGSON B., SHRIVASTAVA P., LEACH M., O'CONNELL D. Integration: the key to implementing the Sustainable Development Goals. Sustainability science, 12 (6), 911, 2017.

72. KROLL C., WARCHOLD A., PRADHAN P. Sustainable Development Goals (SDGs): Are we successful in turning trade-offs into synergies?. Palgrave Communications, 5 (1), 1, 2019 